\title{
ZONEAMENTO AMBIENTAL E DIRETRIZES PARA O PLANO DE MANEJO DO PARQUE DO MORRO EM SANTA MARIA/RS
}

\author{
Eliane Maria Foleto ${ }^{1}$ \\ Patrícia Ziani ${ }^{2}$
}

\begin{abstract}
Resumo: O executivo municipal de Santa Maria/RS tem como proposta instituir uma Unidade de Conservação (UC) de Proteção Integral, na categoria de Parque, em uma área de 156 hectares localizada no Morro do Carmo, denominado de Parque do Morro. Entre as justificativas para instituir essa UC estão o fato de Santa Maria localizar-se no rebordo do planalto e também de possuir áreas definidas pela Unesco como Reserva da Biosfera com significativos remanescentes de Mata Atlântica. Sob tal perspectiva, o artigo tem por objetivo apresentar a caracterização da área estudada, o seu mapeamento, proposta de zoneamento ambiental e diretrizes para subsidiar futuras discussões do plano de manejo. Os procedimentos metodológicos consistiram em leituras sobre a temática da pesquisa, trabalhos, trabalhos de campo, reuniões com o Grupo de Trabalho de Parques Municipais e elaboração de mapas temáticos da área no software livre SPRING 4.3.3. Esses mapas podem servir de argumento para a preservação desse espaço, pois indicam, por exemplo, sua altimetria, declividade, cobertura do solo e zoneamento ambiental, bem como sua localização. Logo, esses resultados subsidiam a criação dessa UC, bem como para a proposta de ampliação dessa área, buscando, assim, efetivar a conservação da biodiversidade presente.
\end{abstract}

Palavras-chave: Unidade de Conservação; Parque do Morro; Zoneamento Ambiental; Santa Maria/RS.

\section{Zoning and Guidelines for Environmental Management Plan of Park Hill in Santa Maria/RS}

Abstract: The municipal executive of Santa Maria/RS has a proposal to establish a Conservation Unit (CU) Full Protection, in the category of Park, in an area of 156 hectares located in the Morro do Carmo, called Park Hill. Among the reasons for instituting this are the fact CU Santa Maria is located on the edge of the plateau and also have areas defined by UNESCO as a Biosphere Reserve with significant remnants of the Atlantic Forest. From this perspective, the article aims to present the characterization of the study area, its mapping, environmental zoning proposal and guidelines to support future discussions of the management plan. The methodological procedures consisted of readings on the subject of the research work, field work, meetings with the Working Group Municipal Parks and elaboration of thematic maps of the area on the Free Software SPRING 4.3.3. These maps can serve as an argument for the preservation of this space, as they indicate, for example, its altitude, slope, land cover and environmental zoning, as well as its location. Thus, these results provide the creation of this $\mathrm{CU}$, as well as the proposed expansion of this area, seeking thereby effecting the conservation of biodiversity present.

Keywords: Conservation Unit, Park Hill; Environmental Zoning; Santa Maria/RS.

\footnotetext{
${ }^{1}$ Graduação em Geografia pela Faculdade de Ciências e Letras Imaculada Conceição, mestrado em Engenharia Civil pela Universidade Federal de Santa Catarina e doutorado em Engenharia de Produção pela Universidade Federal de Santa Catarina. Atualmente é professora Associado I da Universidade Federal de Santa Maria. E-mail: efoleto@gmail.com

${ }^{2}$ Acadêmica do curso de Geografia Licenciatura do Departamento de Geociências da Universidade Federal de Santa Maria. Email: pathyziani@hotmail.com DOI: 10.7154/RDG.2013.0026.0002
} 


\section{INTRODUÇÃO}

Principalmente a partir do século $\mathrm{XX}$, a criação de áreas protegidas surge como reação da sociedade diante dos problemas ambientais e da preocupação com a conservação da biodiversidade do planeta, que se devem à intensa utilização dos recursos naturais pelo homem. Nesse sentido, surge a necessidade de adotar medidas de planejamento e gestão, buscando proteger as áreas naturais para garantir a continuidade dos serviços ambientais prestados à qualidade de vida da sociedade.

Sob essa perspectiva, o município de Santa Maria tem como proposta criar uma Unidade de Conservação (UC) de Proteção Integral, categoria Parque, em uma área de 156 hectares na região norte do perímetro urbano, a qual vem sofrendo pressões em razão da expansão urbana. Essa proposta se qualifica ainda mais pelo fato da área de estudo se localizar em uma área considerada pelo RS Biodiversidade - que é uma política do governo do estado do Rio Grande do Sul para a proteção e conservação dos recursos naturais - como de alta prioridade para a conservação da biodiversidade. Além disso, a área também foi tombada como Reserva da Biosfera Mata Atlântica (RBMA) pela Organização das Nações Unidas para a Educação, a Ciência e a Cultura (Unesco) em 1993.

$\mathrm{Na}$ legislação de Santa Maria também é possível encontrar alguns aspectos em relação a áreas protegidas, como, por exemplo, o Plano Diretor de Desenvolvimento Urbano Ambiental (PDDUA) de Santa Maria, Lei no 034/2005, e a Lei de Uso e Ocupação do Solo, Parcelamento, Perímetro Urbano e Sistema Viário de Santa Maria/Luos (no 072/2009). Contudo, apesar da área do futuro Parque não estar identificada está inserido no anexo 12 como um espaço considerado com Áreas Especiais de Conservação Natural - Reserva da Mata Atlântica.

Diante disso, o artigo visa oferecer subsídios à proposta de instituir essa UC e contribuir para o projeto do plano de manejo do Parque do Morro. Pretende-se contribuir também para discussões referentes às UCs, produzindo novos conhecimentos, uma vez que se trata de um tema regulamentado por políticas públicas e a sociedade, de modo geral, não conhece essa temática. Além disso, poderá, possivelmente, servir de modelo para outras instituições desenvolverem atividades cuja finalidade é a preservação e conservação do meio ambiente. 


\section{Áreas Protegidas}

Desde a criação do primeiro parque nacional, o de Yellowstone, nos Estados Unidos, em 1872, a delimitação de espaços territoriais especialmente protegidos vem sendo utilizada como o principal instrumento da Política Nacional do Meio Ambiente, Lei no 6.938/81, para a proteção da paisagem e da biodiversidade.

O conceito de áreas protegidas é abrangente, integrando diferentes tipologias, como as Áreas de Preservação Permanente (APPs), a Reserva Legal (RL) e as Unidades de Conservação. Desse modo, utilizamos a conceituação da União Mundial para a Natureza (IUCN), que define área protegida como:

Uma superfície de terra ou mar especialmente consagrada à proteção e preservação da diversidade biológica, assim como dos recursos naturais e culturais associados, e gerenciada através de meios legais ou outros meios eficazes. (SCHERL, 2006, p. 7).

Bensusan (2006) ressalta, em relação a esse conceito, que nas Áreas Protegidas aplicam-se medidas restritivas em um determinado território, buscando limitar o uso da terra e dos recursos naturais, uso este que vem se intensificando cada vez mais, devido à ocupação desenfreada da terra e do uso excessivo desses recursos. Porém a implementação dessas áreas tem enfrentado inúmeros obstáculos, entre eles se destacam o modo como essas Áreas Protegidas foram estabelecidas e a pressão exercida sobre elas em relação ao uso dos recursos naturais presentes.

No Brasil, o poder público utiliza a conservação de espaços naturais como uma estratégia para controlar e gerenciar recursos ambientais. A Política Nacional do Meio Ambiente, instituída pela Lei no 6.938/1981, ratifica a criação dessas áreas como um de seus principais instrumentos (BRASIL, 1981).

Para áreas protegidas cujo propósito é a proteção da biodiversidade, ecossistemas e paisagem, utiliza-se o termo "Unidade de Conservação" (UC), que não possui tradução em outros idiomas e pode ser entendido como um subconjunto das áreas protegidas.

\section{Sistema Nacional de Unidades de Conservação da Natureza}

Buscando unificar e organizar as categorias de áreas protegidas no Brasil, é estabelecido no ano de 2000 o Sistema Nacional de Unidades de Conservação da Natureza (SNUC - Lei no 
9.985). Esta lei define critérios e normas para a criação, implantação e gestão das UCs no âmbito nacional, estadual e municipal, definindo-as como:

espaço territorial e seus recursos ambientais, incluindo as áreas jurisdicionais, com características naturais relevantes, legalmente instituído pelo Poder Público, com objetivos de conservação e limites definidos, sob regime especial de administração, ao qual se aplicam garantias adequadas de proteção (BRASIL, 2000, n.p.).

O SNUC é composto por 12 categorias distintas de UCs, divididas em dois grupos: as Unidades de Conservação de Proteção Integral e as Unidades de Conservação de Uso Sustentável. As categorias do primeiro grupo visam preservar a natureza admitindo somente o uso indireto dos recursos naturais, ou seja, não permitindo consumo, coleta, dano ou destruição desses recursos, mas somente atividades de recreação, lazer e pesquisas científicas. Pertencem a esse grupo as categorias Estação Ecológica, Reserva Biológica, Parque Nacional, Monumento Natural e Refúgio de Vida Silvestre (BRASIL, 2000).

Segundo o mesmo autor, as Unidades de Conservação de Uso Sustentável, segundo grupo, admitem o uso direto dos recursos naturais, permitindo a exploração destes de maneira sustentável, garantindo a perenidade dos recursos e processos ecológicos. Nesse grupo encontram-se as categorias: Área de Proteção Ambiental, Área de Relevante Interesse Ecológico, Floresta Nacional, Reserva Extrativista, Reserva de Fauna, Reserva de Desenvolvimento Sustentável e Reserva Particular de Patrimônio Natural.

$\mathrm{Na}$ área de estudo desta pesquisa tem-se como proposta do executivo municipal de Santa Maria, através do escritório da cidade, instituir uma UC de Proteção Integral de categoria Parque Nacional, categoria que visa, segundo o SNUC:

a preservação de ecossistemas naturais de grande relevância ecológica e beleza cênica, possibilitando a realização de pesquisas científicas e o desenvolvimento de atividades de educação e interpretação ambiental, de recreação em contato com a natureza e de turismo ecológico (BRASIL, 2000 , n.p.).

A visitação nessa unidade está sujeita às condições e restrições estabelecidas no Plano de Manejo da Unidade. Já para a realização de pesquisa científica, faz-se necessária a autorização prévia do órgão responsável pela administração da unidade (BRASIL, 2000).

Bensusan (2006) pontua que, no Brasil, as primeiras UCs que se estabeleceram foram justamente os Parques Nacionais, os quais, de início, satisfaziam critérios estéticos; posteriormente, atribuíram-se critérios técnicos para essa definição. 
Uma vez que essa unidade foi proposta pelo município de Santa Maria/RS, ela é de posse do mesmo. Além disso, por se tratar de uma UC, o SNUC estabelece que tenha um plano de manejo, conceituando-o como:

documento técnico mediante o qual, com fundamento nos objetivos gerais de uma Unidade de Conservação, se estabelece o seu zoneamento e as normas que devem presidir o uso da área e o manejo dos recursos naturais, inclusive a implantação das estruturas físicas necessárias à gestão da Unidade de Conservação (BRASIL, 2000, n.p.).

Bensusan (2006) destaca a importância do manejo, assegurando que,

a maior razão para justificar a necessidade de manejar os ecossistemas a serem conservados nas áreas protegidas é a dimensão do impacto humano e suas consequências para a nossa espécie. Por toda parte, as atividades humanas comprometeram a capacidade natural regenerativa $\mathrm{e}$ autossustentável de vários ecossistemas. Se desejarmos mitigar os efeitos de fenômenos como conversão de áreas naturais, espécies invasoras, ampliação da atuação de patógenos, poluição química e industrial, o manejo é ferramenta fundamental (BENSUSAN, 2006, p. 105).

A mesma autora contribui ainda ao afirmar que o plano de manejo visa garantir e restaurar a composição, estrutura e função dos ecossistemas, degradados ou não, tendo como objetivo principal a sustentabilidade em longo prazo (BENSUSAN, 2006).

O plano de manejo é definido como o principal instrumento de planejamento da unidade, estabelecendo o zoneamento e normas da área para a restrição do uso nesta, visando à conservação (IBAMA, 2002). O mesmo assegura que para o cumprimento desses objetivos o planejamento seja:

$\checkmark$ Contínuo, por envolver uma constante busca de conhecimento para manter a proposta de manejo atualizada, pois a cada nova fase sempre englobará os conhecimentos e as ações da fase precedente;

$\checkmark$ Gradativo, devido à evolução dos conhecimentos sobre os recursos naturais e culturais da UC determinante para a capacidade de abrangência do Planejo de Manejo;

$\checkmark$ Flexível, pois consiste na possibilidade de agregar novos conhecimentos e eventuais correções ao plano de manejo durante a implementação de qualquer das fases;

$\checkmark$ Participativo, porque prevê o envolvimento da sociedade no planejamento, através, por exemplo, de Oficinas de Planejamento. 


\section{Zoneamento Ambiental}

Em virtude do uso excessivo da exploração dos recursos naturais, surge a necessidade de um planejamento ambiental. Esse planejamento busca organizar e limitar o uso da terra, consistindo na adequação de ações referentes às potencialidades, vocações e capacidade, visando ao desenvolvimento harmônico da região juntamente com a manutenção/proteção ambiental, proporcionando mais qualidade de vida à sociedade (SANTOS, 2004). Segundo a autora, o planejamento ambiental pode se expressar de diversas maneiras, possuindo instrumentos que auxiliam na execução dos objetivos propostos. Em relação a esses instrumentos, podemos citar estudos de Zoneamento, Plano de Manejo, Planos Diretores e Estudo de Impactos Ambientais.

O zoneamento é definido pelo SNUC na Lei no 9.985/2000 como:

definição de setores ou zonas em uma Unidade de Conservação com propósito de proporcionar os meios e as condições para que todos os objetivos da unidade possam ser alcançados de forma harmônica e eficaz. (BRASIL, 2000, n.p.).

Entre os variados tipos de zoneamento, o que mais condiz com os objetivos do projeto é o Zoneamento Ambiental, que se caracteriza por atuar na identificação das características ambientais (potencialidades, vocações, limites e fragilidades), visando sempre ao menor impacto possível na área, contribuindo para o desenvolvimento sustentável e também para o ordenamento territorial.

Para que haja uma proposta de zoneamento, é necessária a realização de etapas anteriores, como a fase de diagnóstico ambiental, o qual possibilitará conhecer as potencialidades e fragilidades, apontadas a partir da realização de estudos na área de análise (SANTOS, 2004). Desse modo, o diagnóstico ambiental serve para justificar a necessidade de medidas de proteção mesmo antes da instituição da UC, caracterizando-se como um instrumento prévio à elaboração do plano de manejo.

Conforme Santos (2004), é necessário para a seleção e classificação das zonas (ou unidades de zoneamento) o conhecimento sobre a área de estudo, pois a compartimentação destas ocorre a partir da análise das características da área. Dessa forma, para cada unidade de zoneamento serão estabelecidos objetivos e critérios a serem avaliados, definindo então normas, atividades que poderão ser desenvolvidas e a conservação do meio. Assim, cada unidade de zoneamento apresentará características próprias, diferenciando-se umas das outras, apesar de estarem associadas entre si. 
Entre as zonas a serem consideradas na categoria de Parques Nacionais, sugeridas pelo Roteiro Metodológico de Planejamento (IBAMA, 2002), podemos considerar para o Parque do Morro as seguintes:

$\checkmark$ Zona Primitiva: área onde tenha ocorrido pouca intervenção humana, tendo por objetivo preservar o ambiente natural e facilitar as atividades de pesquisa científica e educação ambiental;

$\checkmark$ Zona de Uso Extensivo: constituída em sua maioria por áreas naturais, sendo que o objetivo do manejo é a manutenção do ambiente natural com o mínimo de intervenção humana, mas com acesso público para fins educativos e recreativos;

$\checkmark$ Zona de Uso Intensivo: visa manter o ambiente o mais natural possível, mas permite a construção de infraestrutura de visitação e serviços;

$\checkmark$ Zona de Recuperação: é uma zona provisória, onde só é permitido o uso público para a educação. São áreas visivelmente alteradas pela ação do homem, que têm por objetivo conter essa degradação dos recursos ou restaurar a área. Quando restauradas, passarão a integrar outra zona permanente;

$\checkmark$ Zona de Uso Especial: contém áreas necessárias à administração, manutenção e serviços da UC;

$\checkmark$ Zona de Amortecimento: é o entorno de uma unidade de conservação, onde as atividades humanas estão sujeitas a normas e restrições específicas de uso, com o objetivo amenizar os impactos negativos sobre a unidade.

Essas zonas são classificadas também com base no grau de intervenção. O roteiro também sugere alguns critérios de ajustes para localização e delimitação dessas zonas, como, por exemplo: o nível de pressão antrópica, acessibilidade, regulamentação fundiária, grau de uso, percentual de proteção e limites identificáveis na paisagem.

O Roteiro Metodológico de Planejamento (MMA, 2002) sugere ainda que para a definição de zonas de amortecimento, seja mantido como ponto de partida o limite de $10 \mathrm{~km}$ ao redor da unidade de conservação, estabelecido na Resolução Conama no 13/90 (MMA, 2002).

A partir desse limite aplicam-se critérios de inclusão, exclusão e ajuste das áreas da zona de amortecimento. Entre os critérios de inclusão podemos citar as microbacias dos rios que fluem para a UC, recarga de aquíferos, locais que possam afetar a unidade, como assentamento e polos industriais, áreas com remanescentes ambientais que possam funcionar como corredores ecológicos, áreas com ocorrência de acidentes geográficos e geológicos notáveis, áreas com risco de expansão urbana, entre outros. Nos critérios de não 
inclusão estão áreas urbanas estabelecidas ou já estabelecidas pelo plano diretor municipal ou legalmente instituídas Já o critério de ajuste estabelece limites identificáveis no campo, como linhas férreas, estradas, rios, entre outros, e áreas de influência do espaço aéreo e do subsolo.

No entanto, a Resolução no 428/2010 do Conama, em seu Art. 1으, estabelece novas regras para o licenciamento de empreendimentos de significativo ambiental que comprometem as UCs ou suas áreas circundantes, também chamadas de zonas de amortecimento. Isto é, essa lei estabelece que, para obter a autorização do órgão responsável pela administração da UC, é necessário que sejam realizados estudos de impacto ambiental e, respectivamente, um relatório destes (EIA/RIMA).

\section{Caracterização da Área de Estudo}

O município de Santa Maria/RS está localizado na região central do estado do Rio Grande do Sul, na Depressão Periférica Sul-Rio-Grandense. Conforme IBGE (2010), o município tem uma área total de $1.788,1 \mathrm{~km}^{2}$ e possui cerca de 261.031 habitantes, sendo que $95 \%$ dessa população reside na área urbana.

Heldwein, Buriol e Streck (2009) afirmam que, segundo a classificação de Köppen, o clima da região é do tipo $\mathrm{Cfa}$, ou seja, caracteriza-se como subtropical úmido com verões quentes e sem estação seca definida, pois, uma vez que a umidade relativa do ar é elevada durante todo o ano, acaba por condicionar um clima úmido com chuvas bem distribuídas durante todos os meses. Apesar disso, os autores destacam que, em razão da continentalidade e baixa altitude, Santa Maria é considerada uma das cidades mais quentes do estado do Rio Grande do Sul.

Sartori (2009) identifica, geomorfologicamente, que Santa Maria está inserida na unidade morfoestrutural da Bacia do Paraná. O autor também ressalva a transição de sequência sedimentar de camadas vermelhas com derrames de lava subsequentes, o que possibilitou a formação de duas unidades morfoesculturais diferentes: a Depressão Periférica e a Serra Geral.

Associado à geomorfologia, Dalmolin e Pedron (2009) destacam que o município de Santa Maria tem por característica diferentes tipos de solos, proporcionando variados tipos de usos. Conforme os autores, os solos mais significativos na região são os argissolos, planossolos, gleissolos e neossolos. 
Essas características físicas, juntamente com a vegetação remanescente da Mata Atlântica, proporcionam a Santa Maria uma admirável beleza cênica, compondo, assim, um grande potencial ecoturístico, que une elementos tanto naturais quanto históricos do município.

A área de estudo, na qual se pretende instituir o Parque do Morro, é composta por 156 hectares e encontra-se no Morro do Carmo, também conhecido como Morro da Casinha Branca, localizado na porção norte do município, no rebordo do planalto. A área está inserida na Reserva da Biosfera Mata Atlântica, o que fortalece a importância de proteção desse local.

Além disso, observa-se que, no entorno da área estudada, existe uma forte pressão em relação à expansão urbana e também uma crescente especulação imobiliária, a qual, nos últimos anos, tem focado significativamente ambientes mais naturais. Desse modo, reforçase a importância da proposta de implantação de uma UC, tendo em vista conter esses avanços, uma vez que, se não contidos, certamente causarão impactos ambientais significativos e perda da biodiversidade e qualidade de vida.

A legislação ambiental de Santa Maria apresenta como aspectos importantes em relação a áreas protegidas o Plano Diretor de Desenvolvimento Urbano Ambiental de Santa Maria, Lei no 034/2005, que, conforme seu Art. 1ㅇ, tem por objetivo ordenar o desenvolvimento das funções sociais da cidade e do meio rural, garantindo o bem-estar de seus habitantes. Também de acordo com o plano, algumas das funções sociais da cidade e do meio rural são: o acesso à moradia, saneamento básico, água potável, energia elétrica, saúde, educação, cultura, lazer, segurança e preservação do patrimônio ambiental e cultural.

Nessa mesma lei, encontram-se algumas políticas públicas importantes que contribuem para a área estudada, entre elas estão: premissas de sustentabilidade, políticas de manejo dos recursos naturais urbanos e políticas municipais de manejo sustentável da área de influência da Reserva da Biosfera Mata Atlântica.

Já na Lei de Uso e Ocupação do Solo, Parcelamento, Perímetro Urbano e Sistema Viário de Santa Maria/Luos (no 072/2009), em seu anexo 12, são definidas Áreas Especiais Naturais. No entanto, segundo esse anexo, constatamos que não há referência alguma ao Parque do Morro, mesmo este estando incluído na Reserva da Biosfera Mata Atlântica, o que talvez se justifique pelo fato de que essa proposta é mais recente. 


\section{Reserva da Biosfera Mata Atlântica}

Hoje restam aproximadamente $22 \%$ da cobertura original da Mata Atlântica e apenas $7 \%$ desta está preservada em fragmentos acima de 100 hectares. Mas, apesar de estar muito fragmentada e reduzida, estima-se que na Mata Atlântica existam, aproximadamente, 20 mil espécies vegetais, ou seja, 35\% das espécies existentes no Brasil, incluindo diversas espécies endêmicas e ameaçadas de extinção (MMA, 2012).

Em relação à fauna, estima-se que a Mata Atlântica abrigue 849 espécies de aves, 370 espécies de anfíbios, 200 espécies de répteis, 270 de mamíferos e cerca de 350 espécies de peixes. Desse modo, enfatiza-se que o bioma da Mata Atlântica é altamente prioritário para a conservação da biodiversidade mundial (MMA, 2006).

Como o município de Santa Maria apresenta remanescentes desse bioma, considera-se indispensável que a administração do município estimule, através de políticas, práticas que conservam o meio ambiente. Isso porque, além de preservar a biodiversidade do local, os serviços ambientais prestados pela natureza trazem diversos benefícios, os quais são fundamentais para a manutenção e qualidade de vida da população.

Entre esses benefícios podemos citar: a regularização do microclima local; manutenção do ciclo hidrológico e da qualidade da água; manutenção da biodiversidade e dos recursos genéticos; proteção de espécies ameaçadas de extinção; conservação do solo, mantendo sua estrutura e estabilidade; contribuição na prevenção de riscos; promoção do desenvolvimento sustentável a partir dos recursos naturais; valorização econômica e social sobre a variedade biológica; proteção de paisagens e recursos naturais de notável beleza cênica; desenvolvimento de educação ambiental, como o incentivo à pesquisa científica, do ecoturismo, entre outros (MMA, 2010).

Como podemos observar, os serviços ambientais prestados pela natureza nos trazem diversos benefícios, pois garantem a conservação e recuperação dos ecossistemas e dos seus processos ecológicos, os quais são fundamentais para a manutenção e qualidade de vida da população.

\section{MATERIAIS E MÉTODOS}

O fundamento metodológico utilizado é a abordagem sistêmica, que, aplicada à Geografia, torna possível o estudo do espaço de modo integrado, por considerar a conexão existente 
entre seus componentes antrópicos e seus componentes naturais formadores como uma totalidade indissociável.

Inicialmente, os procedimentos metodológicos consistiram na busca de material bibliográfico e leituras referentes ao tema a ser trabalhado, isto é, Áreas Protegidas, Unidades de Conservação e Zoneamento Ambiental. Posteriormente, foram realizados de trabalhos de campo, reuniões com o Grupo de Trabalho de Parques Municipais, mapeamentos da área de estudo e discussão destes. Entre os materiais utilizados para a realização dos mapas estão:

$\checkmark$ A carta topográfica de Santa Maria, nomenclatura SH-22-V-C-IV/1-SE elaborada pela Diretoria de Serviços Geográfico de escala 1:25.000 e dados disponibilizados pelo escritório da cidade de Santa Maria, o qual mostra o limite do Parque em uma imagem do Google Earth;

$\checkmark$ Software Sistema de Informações Georreferenciadas - SPRING versão 4.3.3- INPE (módulo principal de entrada, manipulação e transformação de dados geográficos, executando as funções relacionadas à criação, manipulação de consulta ao banco de dados, funções de entrada de dados, processamento digital de imagens, modelagem numérica de terreno e análise geográfica de dados); IMPIMA 4.3.3.- INPE (programa para conversão de imagens no formato GRIB); e SCARTA 4.3.3.- INPE (edita uma carta e gera arquivo para impressão a partir de resultados gerados no módulo principal SPRING, permitindo a apresentação na forma de um documento cartográfico, o que possibilita editar textos, símbolos, legendas, linhas, quadros e grades em coordenadas planas ou geográficas).

Assim sendo, com base nos dados disponibilizados pelo escritório da cidade de Santa Maria, delimitou-se a localização geográfica do Parque do Morro e selecionou-se a carta topográfica que contemplasse a área a ser estudada. A partir disso converteu-se a imagem da carta topográfica do formato TIFF para o formato GRIB (grb) no aplicativo IMPIMA 4.3.3., para poder exportá-la depois para o SPRING, onde foram georreferenciadas.

Posteriormente, para a elaboração do projeto do Parque do Morro, criaram-se os Planos de Informação (PIs), que são um conjunto de objetos com características básicas em comum. Estes estão associados a uma categoria e se referem a um modelo de dados que pode ser temático, numérico, imagem, cadastral ou rede. Alguns dos PIs criados foram: limite do parque (modelo temático), rede de drenagem (temático) e curvas de nível (MNT). Estes serviram, basicamente, de base para a elaboração dos mapas. 
Para confeccionar o mapa hipsométrico, criou-se um modelo de dados temático, onde se estabeleceram as classes temáticas, que foram associadas a cores. Esse mapa baseia-se na digitalização das curvas de nível com seus referidos valores altimétricos.

Com base nesse mapa (Figura 1) é possível identificar que a cota mais baixa é de 190 metros e a mais elevada é de 430 metros, Além disso, o relevo foi compartimentado em seis classes de altitude definidas em intervalos de 40 metros com escala gradual de cores para facilitar a visualização e entendimento das diferentes classes.

Quanto à geração do mapa de declividade (Figura 2) criou-se outro modelo de dados temático, no qual também se instituíram as classes temáticas e as cores. Esse mapa baseiase nas curvas de nível, quanto mais próximas forem estas, maior será a inclinação do relevo. Para elaborar desse mapa, utilizaram-se classes temáticas em limites de porcentagem, sendo eles (HERZ; DE BIASI, 1989 apud DE BIASI, 1992):

$\checkmark<5 \%$ : determina o limite urbano-industrial;

$\checkmark$ 5-12\%: define o limite máximo do emprego da mecanização na agricultura;

$\checkmark$ 12-30\%: é o limite máximo para urbanização sem restrições, segundo a Lei no 6.766/79;

$\checkmark$ 30-47\%: segundo o Código Florestal, é o limite máximo de corte raso, a partir do qual a exploração só será permitida se sustentada por cobertura de florestas (Lei no 4.771/65 de 15/09/65);

$\checkmark>47 \%$ : o artigo 10 do Código Florestal prevê que, na faixa situada entre 25은 (47\%) e 45 (100\%), "não é permitida a derrubada de florestas, [...] só sendo tolerada a extração de toros, quando em regime de utilização racional, que vise a rendimentos permanentes".

Buscando salientar essas áreas de declive, realizou-se um mapa de APPs (Figura 3), com base no Código Florestal de 1965 (Lei Federal no 4.771), que indica restrições de uso para as encostas com declividade superior a $45 \%$. Além disso, buscou-se identificar as APPs nascentes dos rios, com buffer de $50 \mathrm{~m}$, e as APPs margens dos rios, com buffers de $30 \mathrm{~m}$ cada.

Na elaboração do mapa de cobertura do solo (Figura 4), fez-se necessária a utilização da imagem de satélite Landsat 5 TM, bandas 3, 4 e 5 resolução 30 metros, datada em 30 de Junho de 2009, a qual foi importada para o SPRING e aplicada às técnicas de contraste na imagem classificada atribuindo-se classes aos diferentes tipos de cobertura do solo: floresta, floresta densa, campo, solo exposto e corpos d'água. 
Para estabelecer esses diferentes tipos de cobertura, utilizaram-se as seguintes definições: floresta, segundo o Sistema Nacional de Informações Florestais, é qualquer vegetação que apresente predominância de indivíduos lenhosos, onde as copas das árvores se tocam formando um dossel; floresta densa são espaços onde a vegetação da floresta é mais densa, visivelmente em melhor estado de conservação; campo são áreas que se caracterizam pela presença de uma vegetação rasteira (gramíneas) e pequenos arbustos; a água é uma substância química composta de hidrogênio e oxigênio, sendo essencial para todas as formas conhecidas de vida; e solo exposto são as áreas que se caracterizam por não apresentarem ou praticamente não apresentarem qualquer tipo de cobertura. Ao final dessas etapas de classificação, gerou-se então o mapa de uso do solo.

Já a confecção do mapa de zoneamento ambiental (Figura 5) teve como base os resultados obtidos na elaboração dos mapas e uma imagem do Google Earth (setembro/2011). Assim sendo, buscou-se ressaltar e cruzar esses dados para então serem definidas as zonas (ou unidades de zoneamento) que seriam estabelecidas.

Para a seleção e classificação dessas zonas, utilizaram-se como base as zonas sugeridas pelo Roteiro Metodológico de Planejamento (IBAMA, 2002) para Parques Nacionais, conforme citado anteriormente.

Por fim, elaborou-se a Figura 6, com base em uma imagem disponível no Google Earth, a qual sugere a ampliação do espaço destinado ao Parque do Morro. Essa figura mostra o perímetro atual do Parque e uma proposta de ampliação deste.

Os critérios utilizados para definir a ampliação desse espaço consistiram em observações e estudos feitos no entorno do Parque, os quais ressaltam que o perímetro do local contempla somente um lado do morro e o topo, como se não houvesse uma relação mútua entre ambos os lados tanto das espécies vegetais e animais quanto da própria dinâmica e estabilidade do morro. Outro aspecto observado e atribuído como critério é a própria localização e formato do Parque, isto é, a ampliação desse espaço, além de incluir áreas declivosas do entorno do Parque, também contribuiria para conter avanços e ocupações populacionais.

Ao término da elaboração dos mapas no IMPIMA e SPRING, utilizou-se o SCARTA, no qual se ativa e trabalha com o projeto do Parque do Morro. No SCARTA estabeleceu-se o layout dos mapas, que foram finalizados em Corel Draw versão 14. 


\section{RESULTADOS E DISCUSSÕES}

O levantamento hipsométrico (Figura 1) feito na área do Parque revelou uma amplitude altimétrica de 240 metros. Diante disso, ressalta-se que toda a área do Parque está na Reserva da Biosfera, porque, no município de Santa Maria, uma área acima de $100 \mathrm{~m}$ de altitude é considerada pertencente à Reserva da Biosfera. Assim, se for instituída a UC, esta passará a área-núcleo da RBMA.

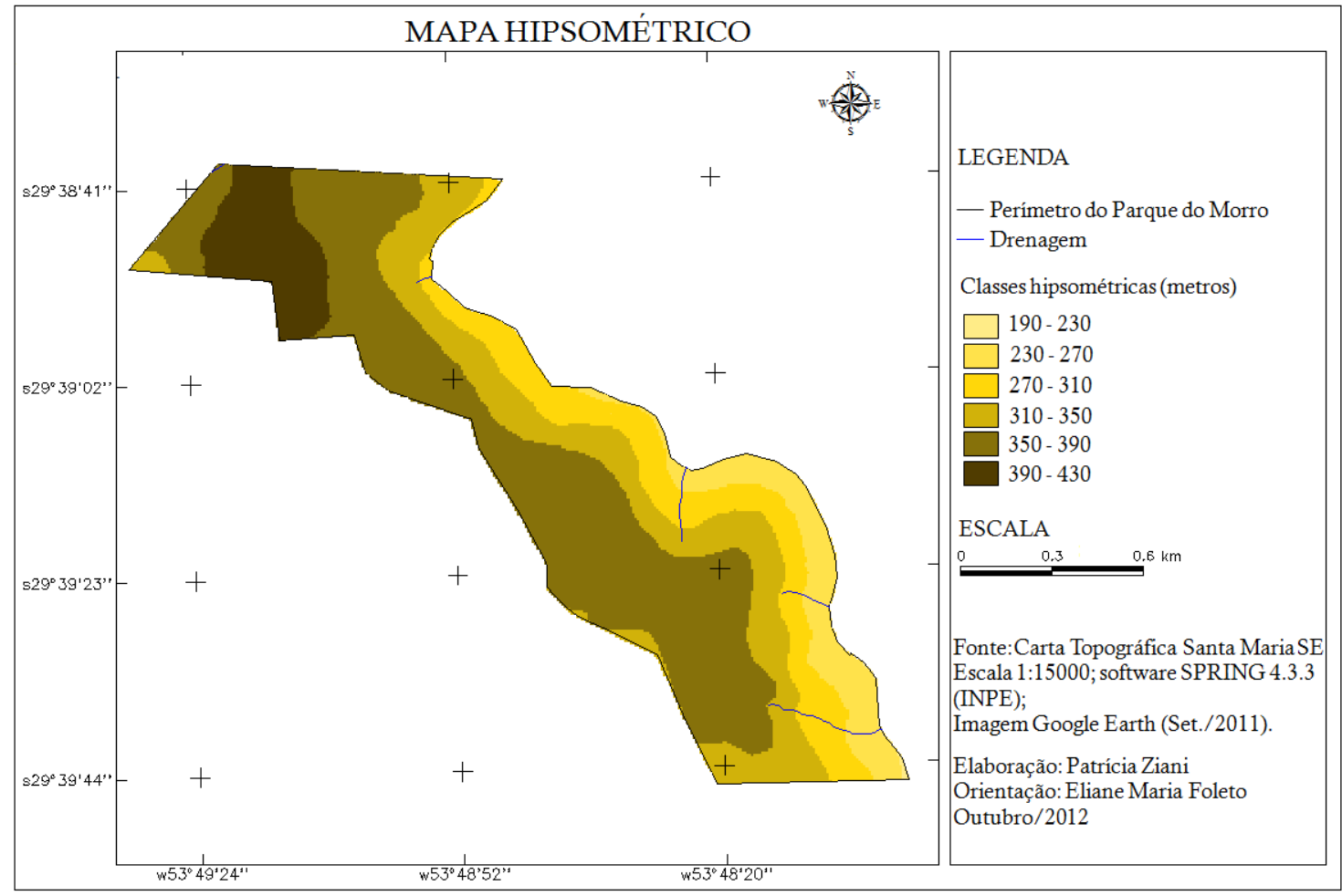

Figura 1 - Mapa hipsométrico do Parque do Morro - Santa Maria/RS Fonte: elaborado por Ziani (2012).

Assim, visualizando o mapa acima (Figura 1), nota-se que o mapeamento indica o gradativo aumento da altitude em direção oeste e noroeste da área de estudo, o que aponta, inicialmente, um aumento na inclinação do relevo e, possivelmente, identificação de APPs, as quais consistem na restrição de uso e ocupação. Diante desses fatos, esse mapa contribui para a análise dos mapas seguintes.

O mapa de declividade (Figura 2) permite expressar as inclinações do relevo juntamente com outras variáveis, fazendo uma correlação que possibilita resultados mais eficazes. 


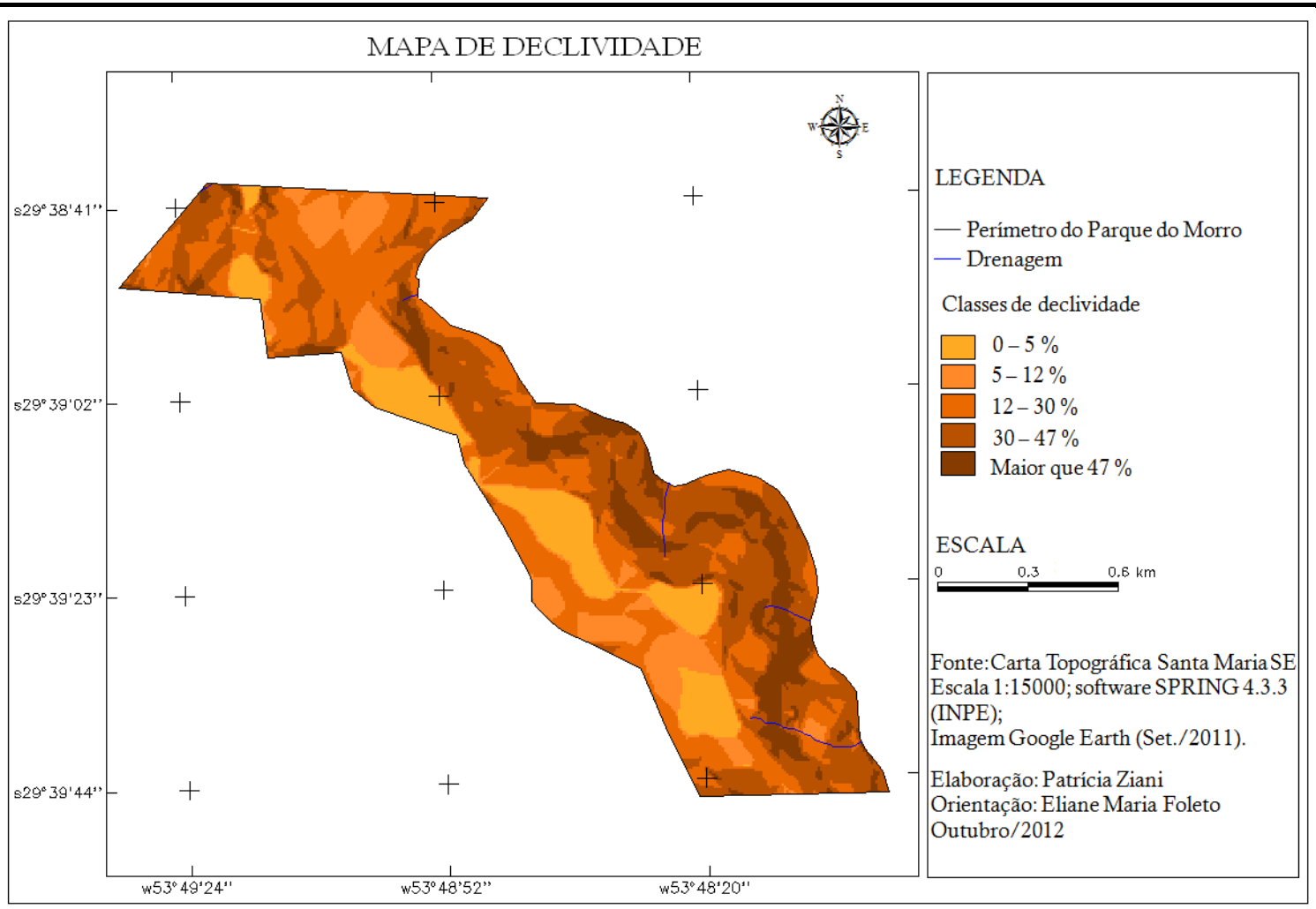

Figura 2 - Mapa de declividade do Parque do Morro - Santa Maria/RS Fonte: elaborado por Ziani (2012).

Nesse mapa nota-se que, ao somarmos as classes de maior declividade ("30 e 47\%" e "maior de $47 \% "$ ), obtém-se uma área aproximadamente de $40 \%$, concentrada na porção leste do Parque, fato que, aliado à presença de densa vegetação arbórea, implica restrições ainda maiores quanto à ocupação desse espaço. Ao mesmo tempo, ressalta-se a importância da permanência dessa vegetação, principalmente nas áreas mais declivosas, pois, se houver a retirada da mesma, aumentará, consequentemente, o escoamento superficial, erosão, instabilidade nas vertentes, riscos de deslizamentos, escorregamentos, entre outros.

Buscando salientar ainda mais essas áreas de declive, realizou-se um mapa das Áreas de Preservação Permanente (APPs) com base no Código Florestal de 1965 (Lei Federal no 4.771), que estabelece como APP encostas com declividade superior a 45\% (Figura 3).

Através dos resultados obtidos, nota-se que as APPs situam-se em um espaço considerável do Parque e que as nascentes dos rios localizam-se em áreas bem declivosas, reforçando ainda mais a necessidade do estabelecimento de medidas de preservação especialmente nessas áreas. 


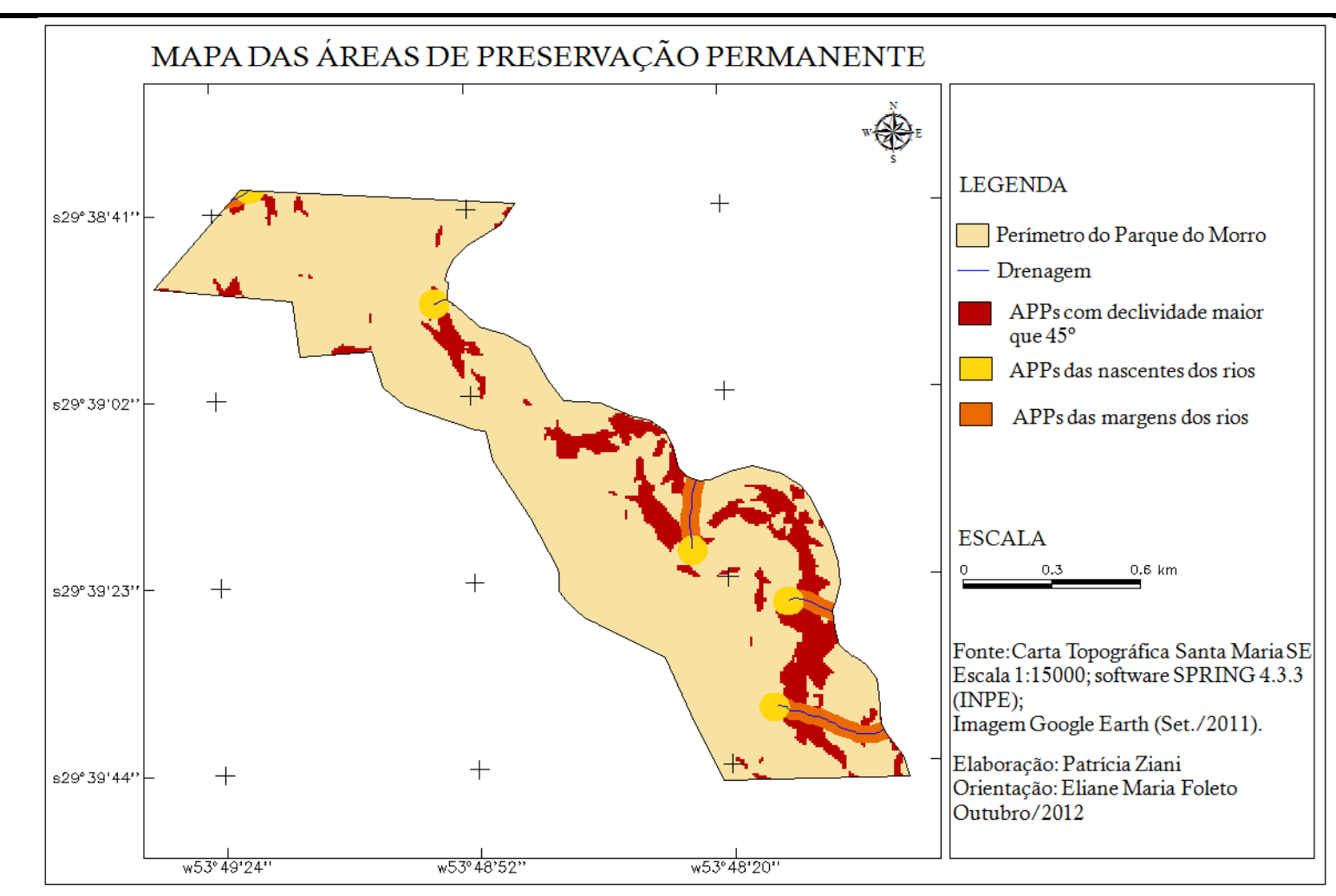

Figura 3 - Mapa de APPs no Parque do Morro - Santa Maria/RS

Fonte: elaborado por Ziani (2012).

No mapeamento de cobertura do solo (Figura 4) a classificação da imagem ocorreu pelo método supervisionado, identificando, assim, as classes temáticas, que foram: floresta, floresta densa, campo, solo exposto e corpos d'água.

Esse levantamento de cobertura do solo é uma ferramenta importante, pois através dele podemos identificar as paisagens geográficas, visualizar os problemas e buscar soluções. Permite também fazer avaliações quali e quantitativas nas modificações provocadas pelas ações do homem em seu meio natural, fornecendo, assim, informações para estabelecer critérios e normas para um manejo mais eficiente tanto de alguns espaços quanto dos recursos naturais.

Para a confecção do mapa de zoneamento ambiental (Figura 5), mesmo optando pelas zonas sugeridas pelo Roteiro Metodológico de Planejamento (IBAMA, 2002) e realizando uma seleção destas com base na realidade do Parque, encontraram-se algumas dificuldades para estabelecer o limite das mesmas. Para as zonas primitivas, por exemplo, a escolha da área leva em consideração pouca intervenção humana, porém nota-se que em todo o perímetro do Parque ocorreram intervenções. Entretanto, algumas áreas já se recuperaram, outras vêm recuperando seu ambiente natural (Figura 5). 


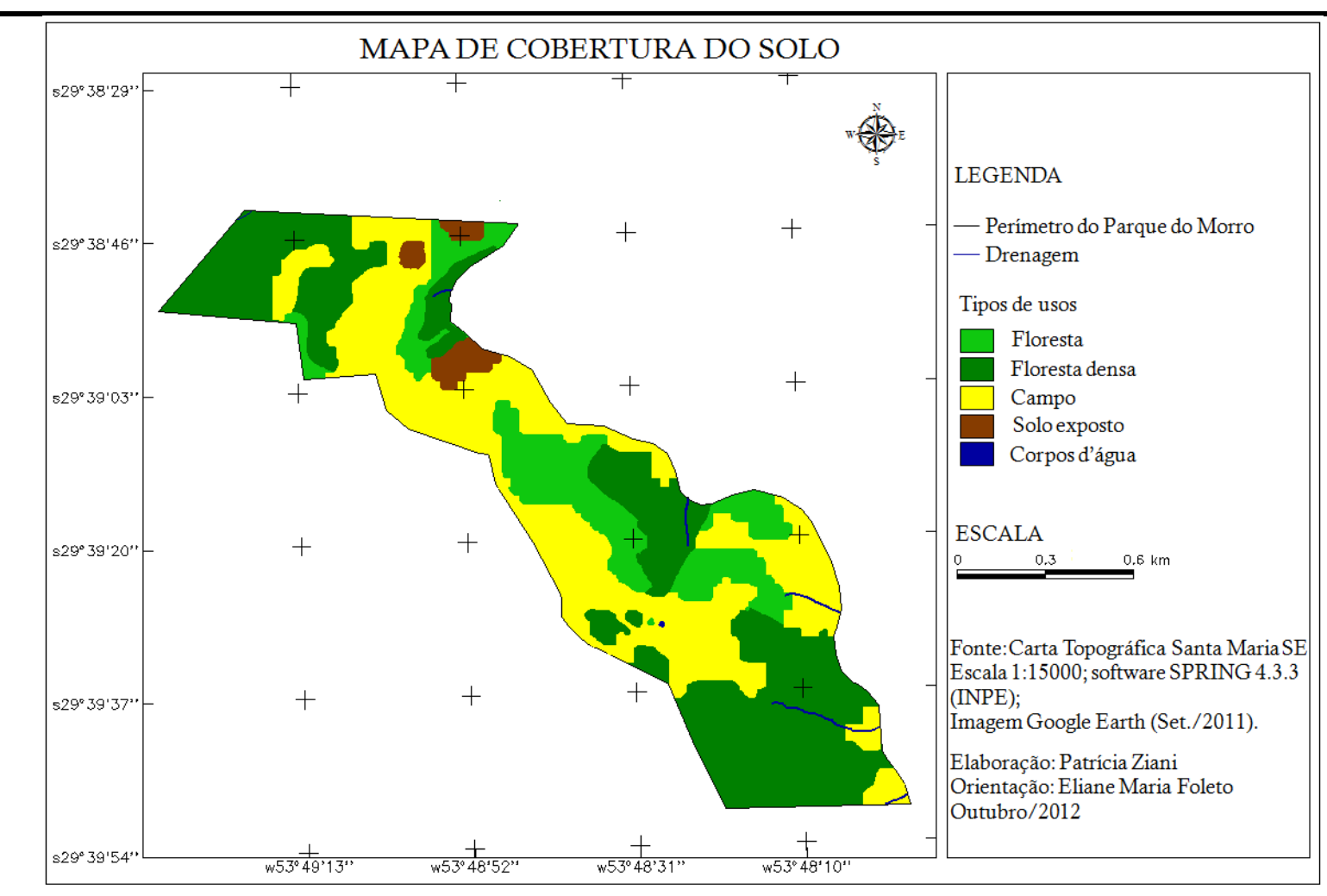

Figura 4 - Mapa de cobertura do solo do Parque do Morro - Santa Maria/RS

Fonte: elaborado por Ziani (2012).

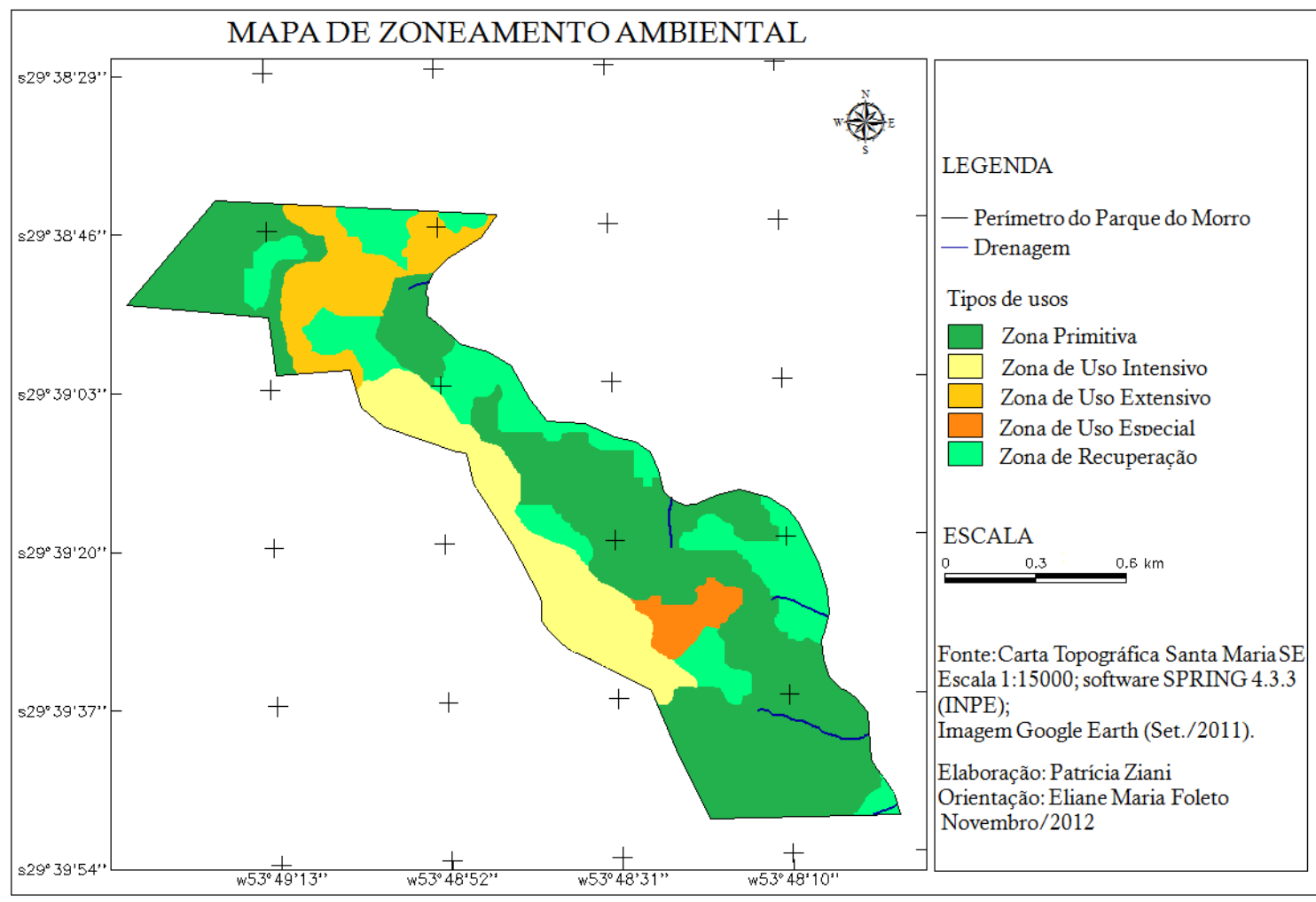

Figura 5 - Mapa de zoneamento ambiental do Parque do Morro - Santa Maria/RS Fonte: elaborado por Ziani (2012).

Com base no mapa acima (Figura 5), nota-se que a zona primitiva ocupa a maior extensão do Parque. Nessa zona, buscou-se incorporar as áreas que careciam de maior restrição de uso, 
pois ali se localizam basicamente as APPs, permitindo, assim, somente atividades de pesquisa científica e educação ambiental.

Na zona de uso intensivo observa-se que esta acompanha boa parte oeste do limite do Parque, região esta que apresenta no máximo $12 \%$ de declividade em alguns trechos, porém de altitudes elevadas. Em razão dessas características e, principalmente, de sua localização, possibilita uma visão incrível da paisagem natural e também da cidade de Santa Maria. Por essa zona possibilitar também a construção de infraestrutura de visitação e serviços, mantendo, evidentemente, o ambiente o mais natural possível, entendemos que nessa área poderia ser construído algum mirante que contemplasse esse panorama.

Já a Zona de Uso Extensivo constitui-se de áreas naturais, com florestas e campos com declividade relativamente média, nas quais podem se realizar algumas atividades de fins educativos e de recreação, pois o acesso ao público é permitido. Porém essas atividades devem gerar o menor impacto possível, afinal essa zona tem por objetivo a manutenção desse ambiente natural.

Em virtude da proximidade do centro urbano e das sedes administrativas municipais, entende-se que a zona de uso especial não carece de um espaço muito significativo, afinal o Parque tem por objetivo incluir o maior espaço, buscando a conservação do meio natural, por isso essa é a zona de menor extensão.

Para estabelecer a zona de recuperação foram utilizados principalmente os resultados obtidos no mapa de APPs e cobertura do solo. Com estes foi possível perceber, por exemplo, que em algumas APPs não existe uma cobertura vegetal adequada para essas áreas. Além disso, nessa zona identificaram-se também as áreas mais degradadas do Parque, as quais precisam ser recuperadas.

Cabe destacar que o estabelecimento dessas zonas auxilia na elaboração do plano de manejo, pois cada zona apresenta objetivos e normas de atividades que poderão ser desenvolvidas ou não, ou seja, determinam o grau de intervenção. Desse modo, o plano de manejo dispõe de uma ferramenta que auxilia na formação e estabelecimento de diretrizes para o manejo da UC.

Diante dos resultados apresentados até então, foi possível observar que a área do Parque envolve apenas uma parte do morro, isto é, o lado leste até o topo, deixando de fora uma porção ao sul e a oeste, onde se encontram áreas com maior declividade e preservação, em virtude de serem APPs, as quais sofrem significativa pressão da expansão urbana e imobiliária. 
Diante disso cabe questionar o perímetro do Parque, pois, se o verdadeiro objetivo de instituir essa UC, categoria Parque Nacional, é de preservar os ecossistemas de grande relevância ecológica e beleza cênica ali presentes, nada mais lógico do que agregar ao Parque o outro lado do morro, onde se encontram áreas que apresentam significativos remanescentes da Reserva da Biosfera Mata Atlântica com altas declividades e suscetíveis a tais pressões.

A figura 6 mostra uma possível proposta de ampliar o perímetro do Parque do Morro. Entre as justificativas para a ampliação do parque está o fato de que, quanto maior for esse limite de extensão, maior será a conservação da UC. Ao mesmo tempo, essa ampliação serviria para conter o avanço da expansão urbana nessa área, contribuindo, assim, para a continuidade das funções ambientais de todo o morro, proporcionando uma maior conservação e manutenção da biodiversidade, o que, consequentemente, gera mais qualidade ambiental e de vida para a população santa-mariense.

A ampliação do perímetro do Parque seria de fundamental importância para a preservação dessa área, pois, além de preservar a biodiversidade presente, contribuiria também para que essa área não seja habitada, uma vez que o Parque é de proteção integral.

Entretanto, considerando que a desapropriação de áreas pelo poder público é bastante demorada e que essa área é ameaçada pela ocupação irregular, o poder público deveria, por exemplo, agilizar a implantação da área de Proteção Ambiental (APA) do Vacacaí-Mirim proposta pela Mestre em Geografia Dalvana Brasil do Nascimento -, a qual abrange áreas públicas e privadas. A criação dessa APA protegerá a diversidade biológica dessa área, na qual se inclui o Parque e seu entorno, e também disciplinará o processo de ocupação, assegurando a sustentabilidade dos recursos ambientais, pois permite um manejo sustentável, desde que sujeita ao zoneamento e ao plano de manejo. Ainda, a APA do Vacacaí-Mirim serviria como zona de amortecimento para o Parque e também possibilitaria ao comitê gestor impor mais restrição nesse entorno, contribuindo ainda mais para a proteção ambiental do Parque. 


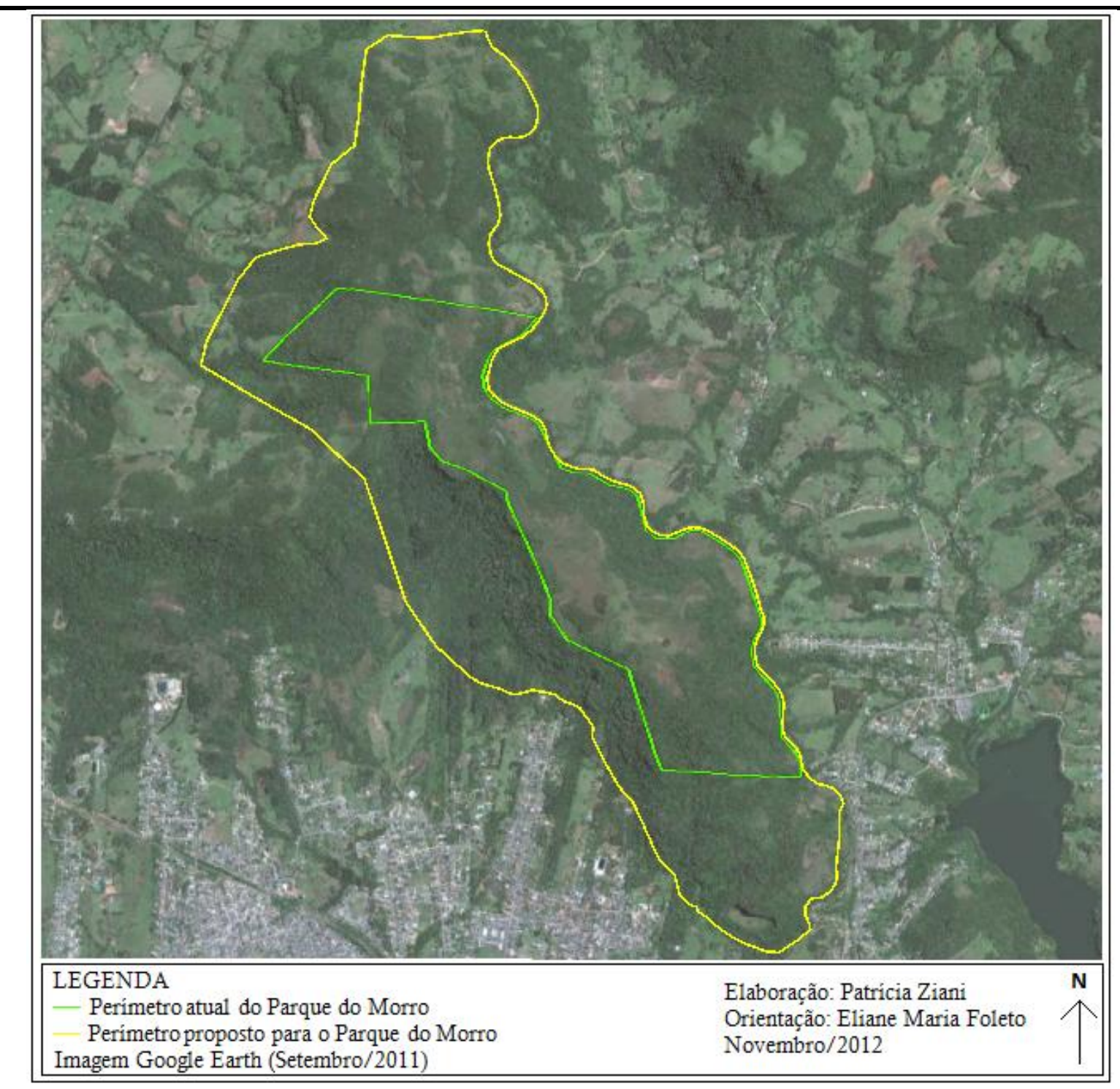

Figura 1 - Proposta de ampliação do perímetro do Parque do Morro Fonte: elaborada por Ziani (2012).

\section{CONSIDERAÇÕES FINAIS}

Este artigo buscou subsidiar a criação do projeto do Parque do Morro, como UC, visando à complementação das funções ambientais do topo do morro, da vegetação das encostas e das nascentes de cursos d'água presentes, proporcionando a preservação e qualidade destes, além da conservação e manutenção da biodiversidade, servindo para manter a qualidade ambiental da área. Além disso, buscamos também contribuir, através do zoneamento ambiental, na elaboração do plano de manejo.

Ressaltamos que as UCs e outras Áreas Protegidas não devem ser vistas como um obstáculo, pois é principalmente nessas áreas que os serviços ambientais são desenvolvidos, os quais 
são usufruídos pelo ser humano tanto direta quanto indiretamente. A instituição de Áreas Protegidas configura-se como o principal meio para a proteção ambiental no Brasil.

Entre os resultados obtidos que ressaltam a importância de se instituir o Parque do Morro estão tanto a proximidade do centro urbano quanto a localização em uma cota acima de 100 m de altitude, fato este que ocasiona, consequentemente, a esta área do Parque o pertencimento direto à Reserva da Biosfera. Se for realmente instituída essa UC, passará a ser área-núcleo da RBMA.

Com relação ao zoneamento ambiental, observamos que são significativos os espaços do Parque que devem ser recuperados em virtude da degradação e ausência de cobertura adequada.

Cabe lembrar que os limites estabelecidos para cada zona nesse projeto não devem ser considerados imutáveis e ser observados rigidamente, pois se tratam de uma proposta, indicações iniciais, que podem e devem ser revistas, tanto para a criação de novas zonas e/ou mudança de limites das já estabelecidas, assim como também para a adoção de outros critérios de avaliação e incorporação de novas informações para auxiliar nessa reavaliação das zonas.

Também é de suma importância que se façam estudos biológicos na extensão do Parque do Morro e em seu entorno, buscando verificar os componentes bióticos e abióticos existentes nessa área. Tais estudos contribuiriam para qualificar este estudo, bem como contribuir para a identificação de áreas que podem/devem ser mais restritivas ou não em virtude de tais componentes.

Todavia, apesar das relevâncias abordadas até então sobre a importância de se instituir uma UC, cabe destacar que não adianta somente instituir uma UC, deve haver também a eficácia da gestão através de um planejamento de manejo e fiscalização nessa área, possibilitando, assim, a manutenção e conservação desta.

\section{REFERÊNCIAS BIBLIOGRÁFICAS}

BENSUSAN, N. Conservação da biodiversidade em áreas protegidas. Rio de Janeiro: FGV, 2006.

BRASIL. Lei n. 9.985, de 18 de julho de 2000. Regulamenta o art. 225, § 1으, incisos I, II, III e VII da Constituição Federal, institui o Sistema Nacional de Unidades de Conservação da Natureza e dá outras providências. Brasília, 2000. Disponível em: <http://www.planalto.gov.br/ccivil_03/leis/L9985.htm>. Acesso: 6 set. 2012. 
. Lei Federal n. 6.938 de 31 de agosto de 1981. Dispõe sobre a Política Nacional do Meio Ambiente, seus fins e mecanismos de formulação e aplicação, e dá outras providências. Presidência da República - Casa Civil, Brasília, DF, 31 ago. 1981. Disponível em: <http://www.planalto.gov.br/ccivil_03/Leis/L6938.htm>. Acesso em: 9 nov. 2012.

DALMOLIN, R. S. D.; PEDRON, F. A. Solos do município de Santa Maria. Ciência \& Ambiente, Santa Maria, n. 38, p. 59-78, jan./jun. 2009.

DE BIASE, M. A carta clinográfica: os métodos de representação e sua confecção. RDG Revista do Departamento de Geografia - USP, São Paulo, v. 6, p. 45-60, 1992.

HELDWEIN, A. B.; BURIOL, G. A.; STRECK, N. A. O clima de Santa Maria. Ciência \& Ambiente, Santa Maria, n. 38, p. 43-58, jan./jun. 2009.

INSTITUTO BRASILEIRO DE GEOGRAFIA E ESTATístICA. IBGE. Sinopse do Censo Demográfico 2010, Rio Grande do Sul. 2010. Disponível em: <http://www.censo2010.ibge.gov.br/sinopse/index.php?dados=21\&uf=43>. Acesso em: 3 set. 2012.

MINISTÉRIO DO MEIO AMBIENTE. MMA. Biomas - Mata Atlântica. 2012. Disponível em: <http://www.mma.gov.br/biomas/mata-atlantica>. Acesso em: 7 set. 2012.

Conselho Nacional do Meio Ambiente (Conama). Resolução no 428, de 17 de dezembro de 2010. Brasília, 2010. Disponível em: <http://www.mma.gov.br/port/conama/legiabre.cfm?codlegi=641>. Acesso em: 19 de jun. 2013.

Roteiro metodológico de planejamento - Parque Nacional, Reserva Biológica, Estação Ecológica. Ibama, 2002.

SANTA MARIA. Lei Complementar municipal n. 034 de 29 de dezembro de 2005. Dispõe sobre a Política de Desenvolvimento Urbano e sobre o Plano Diretor de Desenvolvimento Urbano Ambiental do Município de Santa Maria. Prefeitura Municipal de Santa Maria, Santa Maria, $\quad$ RS, 292 dez. 2005.2 Disponível em: <http://www.santamaria.rs.gov.br/docs/leis/lc_034_plano_diretor.pdf>. Acesso em: 6 set. 2012.

Lei Complementar municipal n. 072 de 4 de novembro de 2009. Institui a Lei de Uso e Ocupação do Solo, Parcelamento, Perímetro Urbano e Sistema Viário do Município Santa Maria. Prefeitura Municipal de Santa Maria, Santa Maria, RS, 4 nov. 2009. Disponível em: <http://www.santamaria.rs.gov.br/docs/leis/Im_72_uso_

solo.-pdf>. Acesso em: 6 set. 2012.

SANTOS, R, F. dos. Planejamento ambiental: teorias e prática. São Paulo: Oficina de Textos, 2004.

SARTORI, P. L. P. Geologia e geomorfologia em Santa Maria. Ciência \& Ambiente, Santa Maria, n. 38, p. 19-42, jan./jun. 2009.

SCHERL, L. M. et al. As áreas protegidas podem contribuir para a redução da pobreza? Oportunidades e limitações. Reino Unido: IUCN, 2006. 60 p. 
SISTEMA Nacional de Informações Florestais. Definição de floresta. Disponível em: <http://www.florestal.gov.br/snif/>. Acesso em: 10 jun. 2013.

Artigo recebido em 20/08/2013.

Artigo aceito em 24/09/2013. 